\title{
O TRABALHO DO PROFESSOR DE PORTUGUÊS: UM ENFOQUE NOS PCN
}

\author{
EL TRABAJO DEL PROFESOR DE PORTUGUÉS: UN ENFOQUE EN LOS PCN
}

\author{
THE PORTUGUESE TEACHER WORK: FOCUSING ON THE NATIONAL CURRICULUM PARAMETERS
}

\author{
Ana Lucia Cheloti Prochnow* \\ Adriana Silveira Bonumá Bortolini*** \\ Silvana Schwab do Nascimento**** \\ Universidade Federal de Santa Maria - UFSM, BR
}

\begin{abstract}
RESUMO: As políticas públicas, a cultura e a sociedade de cada época imprimem sua marca histórica na constituição das práticas escolares e na forma como se preconiza o profissional de língua. Nesse sentido, o presente trabalho tem como objetivo identificar as atribuições do professor de Língua Portuguesa subjacentes aos Parâmetros Curriculares Nacionais - Terceiro e Quarto Ciclos - de Língua Portuguesa (PCN). Entendemos que, para se chegar a esse objetivo, faz-se necessária, inicialmente, a realização de um apanhado histórico da constituição do ensino da Língua Portuguesa no Brasil e, depois, a investigação das atribuições que são confiadas ao professor de Português nos PCN. Para tanto, este trabalho se fundamenta em Bunzen (2011), Soares (2002) e Pietri (2010), que tratam da constituição do ensino da Língua Portuguesa no Brasil; e em Bunzen (2011) e Pietri (2007), que abordam questões referentes ao trabalho docente em documentos oficiais, dentre outros
\end{abstract}

PALAVRAS-CHAVE: Professor de Português; atribuições docentes; Parâmetros Curriculares Nacionais.

RESUMEN: Las políticas públicas, la cultura y la sociedad de cada época imprimen su marca histórica en la constitución de las prácticas escolares y en la forma cómo se preconiza el profesional de lengua. En ese sentido, el presente trabajo tiene como objetivo identificar las atribuciones del profesor de Lengua Portuguesa subyacentes a los Parâmetros Curriculares Nacionais - Tercero y Cuarto Ciclos - de Lengua Portuguesa (PCNs). Comprendemos que, para conquistar ese objetivo, es necesario, inicialmente, la realización de un recorrido histórico de la constitución de la enseñanza de la Lengua Portuguesa en Brasil y, luego, la investigación de las atribuciones que son confiadas al profesor de Portugués en los PCNs. Para tanto, este trabajo se fundamenta en Bunzen (2011), Soares (2002) y Pietri (2010), que tratan de la constitución de la enseñanza de la Lengua Portuguesa en Brasil; y en Bunzen (2011) y Pietri (2007), que abordan cuestiones referentes al trabajo docente en documentos oficiales, entre otros.

PALABRAS-CLAVE: Profesor de Portugués; atribuciones docentes; Parâmetros Curriculares Nacionais.

ABSTRACT: Public policies, culture and the society of every given period of time leave their historical marks in the constitution of school practices and in the way how the language professional must act. Thus, this work aims to identify the attributions of the Portuguese teacher underlying the National Curriculum Parameters - 3rd and 4th cycles - Portuguese Language (PCN). We understand that in order to achieve this objective it is necessary to carry out a historical study about the constitution of Portuguese language teaching in Brazil and afterwards to investigate the attributions which are expected from the Portuguese teacher in the PCNs. To do so, this work is based on Bunzen (2011), Soares (2002) and Pietri (2010), who studied the Portuguese language teaching constitution in Brazil and also based on Bunzen (2011) and Pietri (2007), who approach questions related to teaching work on official documents, among others.

KEYWORDS: Portuguese teacher; teaching attributions; National Curriculum Parameters.

\section{INTRODUÇÃO}

Os estudos em torno da constituição das disciplinas escolares e, da mesma forma, do ensino da Língua Portuguesa no Brasil têm contribuído ao professor de Português, pois lhe possibilitam obter "respostas" para determinados procedimentos e práticas que, até então, pareciam neutras e da vontade de cada profissional. A partir de uma leitura atenta desses trabalhos, a todo momento, se justifica o porquê de, em uma determinada época, as aulas de língua materna serem conduzidas de uma ou de outra maneira e o porquê de um ou outro método de ensino serem privilegiados.

Trabalhos como o de Soares (2002), Angelo (2005), Bunzen (2011), para citar alguns, assumindo uma perspectiva histórica, esclarecem que as práticas escolares encontram-se historicamente marcadas pelas

\footnotetext{
*Email: alchelotti@yahoo.com.br

**Email: a.bonuma@gmail.com

*** Email: silvana_schwab@hotmail.com
} 
políticas públicas, pela cultura e pela sociedade de cada época, e legitimadas nos livros escolares e nos documentos oficiais. Da mesma maneira, trazem evidências de que, em cada momento histórico, desde o Século XVI, em que a educação estava ligada à tradição oral, até à contemporaneidade, ao professor são preconizadas competências e atribuições diversas.

Nesse sentido, este trabalho se propõe analisar os Parâmetros Curriculares Nacionais (doravante PCN), editados em 1998, com o intuito de investigar quais são as atribuições que esse documento confia ao professor de Português.

O embasamento teórico que norteará essa investigação compreende os estudos de Bunzen (2011), Soares (2002) e Pietri (2010), que tratam o ensino da Língua Portuguesa numa perspectiva histórica; e os de Bunzen (2011) e Pietri (2007), cujos estudos discutem o trabalho docente em documentos oficiais.

Para tanto, este trabalho está dividido em quatro partes. Inicialmente, foi realizado um apanhado histórico do surgimento e da ascensão da disciplina escolar Português no Brasil. A seguir, foi feita uma descrição dos Parâmetros Curriculares Nacionais. O terceiro momento refere-se à análise propriamente, em que se discute quais são as atribuições do professor subjacentes nos PCN. Nas considerações finais, busca-se refletir em que medida os PCN esclarecem efetivamente as atribuições docentes, identificando como os professores de Língua Portuguesa devem realizar suas atividades em sala de aula.

\section{A DISCIPLINA LÍNGUA PORTUGUESA NO BRASIL: HISTÓRIA E CONSTITUIÇÃO}

No artigo "Português na escola: História de uma disciplina curricular", Magda Soares afirma que a inclusão da disciplina Língua Portuguesa no currículo escolar foi muito tardia no Brasil uma vez que só ocorreu nas últimas décadas do século XIX, já no fim do Império.

Porém, a história e a constituição dessa disciplina escolar devem ser consideradas desde o Brasil colonial, período em que a Língua Portuguesa, a língua geral e o latim conviviam juntos. A Língua Portuguesa era a língua trazida pelo colonizador, a língua geral era uma mescla das línguas indígenas faladas nos primeiros tempos do Brasil e o latim era utilizado no ensino secundário e superior jesuítico.

Conforme Bunzen (2011), no início do século XVI, na educação, predominava o trabalho com a oralidade e havia uma ligação às necessidades do grupo em que o trabalho era realizado. $\mathrm{O}$ maior objetivo desse momento era doutrinar as crianças segundo os princípios católicos ao lado de disciplinar o corpo e o aprendizado dos três elementos básicos: ler, escrever e contar. Conhecer os fundamentos da doutrina cristã e falar Português eram pré-requisitos para as crianças iniciarem a escola de ler e escrever.

O auge da educação jesuítica foi o período entre 1549 a 1570. As ideias pedagógicas do Pe. Manuel da Nóbrega intencionavam formar o maior número possível de adeptos do catolicismo. Para isso, foi preciso lançar mão do ensino oral do Português, e os evangelizadores tiveram a necessidade de aprender as línguas indígenas pelo convívio e contato com os índios.

No entanto, segundo Bunzen, após a morte do Pe. Manuel da Nóbrega, o aprendizado oral do Português foi praticamente excluído do currículo. "Em seu lugar, surgem as práticas pedagógicas baseadas na Ratio Ataque Instituto Studiorum Societas Jesu (1599), ou seja, um currículo inspirado numa visão retóricogramatical da cultura humanística".(BUNZEN, 2011, p.34).

A Ratio Studiorum, não dedicando nenhum espaço ao estudo da língua materna ou oficial/nacional, tinha como uma de suas finalidades proporcionar o bom conhecimento dos clássicos e o uso correto das línguas latinas e gregas. Era exigido do professor o domínio do latim, da língua do Lácio, representante oficial da classe dominante e do clero. Havia, portanto, uma supremacia do latim sobre a língua vernácula, pois, até o fim da Idade Média, o latim era a língua utilizada para escrever na Europa.

No Brasil, tal situação de dependência da cultura brasileira à da Europa só vai ser modificada "com a implementação de políticas que defendiam o papel das línguas nacionais no processo de escolarização no Ocidente." (BUNZEN, 2011, p. 890). 
Para o referido autor, entre os séculos XVII e XVIII, no cenário europeu, as línguas dos Estados adquiriram maior status na constituição dos saberes escolares. Apesar de já nessa época haver uma produção significativa de gramática, de dicionários e de trabalhos que defendiam o ensino de Português, ainda não havia se constituído uma área de conhecimento em condições de gerar uma disciplina escolar.

Porém, na segunda metade do século XVIII, o uso do idioma Português em território brasileiro passou a ser obrigatório. Marquês de Pombal proíbe o uso de outras línguas, com a finalidade de garantir o poder sobre as colônias, e torna obrigatório o uso do Português no Brasil.

Com a necessidade política de ensinar a língua da metrópole para preservá-la e passá-la aos povos dominados, a reforma pombalina consolidou uma política de expansão linguística de uso interno e externo, pois, do ponto de vista político, foi a maior responsável pelo ensino obrigatório da Língua Portuguesa em Portugal e no Brasil. (BUNZEN, 2011, p.891).

Com a carta régia de 12 de setembro de 1757, que marcaria oficialmente o nascimento da Língua Portuguesa no Brasil, segundo alguns estudiosos da área, Marquês de Pombal obrigou os colonos a ensinar aos povos indígenas a Língua Portuguesa europeia, impedindo, assim, a prática pedagógica jesuítica de utilizar a "língua geral" para catequizar os índios brasileiros.

A partir disso, no Brasil, a Língua Portuguesa começou a ser utilizada nas disciplinas denominadas Gramática, Retórica e Poética, disputando com o latim. Segundo Soares (2002), por essa razão, em um primeiro momento, o ensino do Português seguiu a tradição do latim, mas com enfoque na gramática. Gramática e retórica, portanto, predominaram desde as reformas pombalinas até fins do século XIX na área de estudo da língua. O estudo da gramática do Português, entretanto, é visto como apoio para a aprendizagem da gramática latina, permanecendo durante quase todo o século XIX ainda dependente do latim.

A gramática da Língua Portuguesa só foi ganhando autonomia à medida em que o latim foi perdendo seu uso e valor social. Conforme Soares (2002), foi somente em 1837, com a criação do Colégio Pedro II, no Rio de Janeiro, que o estudo da Língua Portuguesa foi efetivamente incluído no currículo sob as formas das disciplinas Retórica e Poética e, em 1837, o regulamento do colégio passa a mencionar a gramática nacional como objeto de estudo.

Assim, em 1862, as três disciplinas voltadas para o estudo do idioma nacional foram agrupadas sob a denominação de Português, apenas no $1^{\circ}$ ano. Porém, até o fim do período imperial, se ampliou devido a sua inclusão nos chamados "exames preparatórios" e com a criação do cargo de professor de Português em 1871.

No fim do século XIX e início do século XX, as reformas ocorridas apontam justamente para a permanência do ensino de Português nas quatro séries iniciais do secundário com a carga horária de dez aulas semanais. Assim, antes mesmo da emergência do nacionalismo republicano, houve a ascensão do Português como disciplina escolar no currículo da escola secundária brasileira. (BUNZEN, 2011, p.895)

Nas primeiras quatro décadas do século XX, o ensino da gramática do Português passou a ter autonomia devido à progressiva perda do valor do ensino do latim, segundo Soares (2002). Efetivamente em junho de 1931 a disciplina passa a ser denominada Português, com objetivos e conteúdos determinados pelo decreto 19.890 de 1931, documento oficial da fundação do Ministério da Educação e da Saúde Pública na década de 30, que consolidou os programas oficiais e as disciplinas específicas para cada série do secundário.

Nesse período, para atingir os objetivos estabelecidos pela referida regulamentação, a disciplina Português deveria trabalhar a leitura de textos literários, compreendidos como essenciais para fomentar a inteligência dos estudantes e ajudá-los a serem bons redatores de texto.

Na década de 40 do século XX, o ensino da língua materna voltou-se para o sentimento nacionalista, o que intensificou ainda mais o trabalho com a língua literária e o respeito pelo patrimônio nacional. O papel do professor era despertar no aluno o amor pela língua pátria e o gosto literário. 
A partir dos programas de Português de 1942 e 1951, a disciplina passou a apresentar uma reconfiguração com o movimento de permanência e ruptura de objetos de ensino e aspectos metodológicos, o que permitiu ocorrerem alterações de algumas caraterísticas das aulas de Português e dos perfis dos livros didáticos.

Com isso, os textos trabalhados eram selecionados conforme os temas definidos pelos programas, como, por exemplo, a família. Especificamente o programa de 1951 prescrevia que as aulas deveriam ter interpretação de textos de leitura, exercícios de linguagem oral, questões de gramática, vocabulário e redação. Esse programa privilegiava exercícios práticos de gramática e de textos literários.

Ainda, nesse período, a partir dos anos 50, em função das transformações sociais e culturais e das possibilidades de acesso à escola, o conteúdo da disciplina Língua Portuguesa sofreu consideráveis modificações. Até esse momento, a gramática e a coletânea de textos eram dois materiais independentes, porém, a partir daí, gramática e texto passam a ser uma disciplina de conteúdo articulado. Segundo Pietri (2010),

num processo que inicia nos anos 1950 e se consolida na década de 1960, a fusão de gramática e livro de textos faz-se de forma progressiva, e os manuais passam a apresentar exercícios de vocabulário, de interpretação, de redação e de gramática. Estuda-se a gramática a partir do texto e vice-versa, com primazia conferida àquela. (PIETRI, 2010, p.74)

Esse momento é marcado, consequentemente, pelo início do processo de depreciação da função do professor em vista de que começa a ser transferida ao livro didático a tarefa de preparar aulas e exercícios.

A reforma do ensino brasileiro, na década de 70, por meio da lei n 5.692/71, ampliou a obrigatoriedade escolar para oito anos. O Governo Militar, baseando-se em uma tendência tecnicista da educação, voltada para o mundo do trabalho, busca formar trabalhadores, prevalecendo o ensino técnico. Por isso, a educação se coloca a serviço do desenvolvimento.

Em vista disso, a disciplina Português passou a ser um instrumento de comunicação por excelência, assumindo um caráter instrumental e sendo chamada de Comunicação e Expressão em Língua Portuguesa.

A concepção da língua como sistema, prevalente até então no ensino da gramática, e a concepção da língua como expressão estética, prevalente inicialmente no ensino da retórica e da poética e, posteriormente, no estudo de textos, são substituídas pela concepção da língua como comunicação. (SOARES, 2002, p. 169)

Portanto, os objetivos do ensino do Português passaram a ser pragmáticos e utilitários tendo que dar conta de desenvolver e aperfeiçoar os comportamentos dos alunos como emissor e recebedor de mensagens por meio do uso e da compreensão de diversos códigos. Dessa forma, são totalmente contrários a uma educação humanística tradicional.

No fim dos anos 70 e início dos anos 80 do século XX, o ensino a Língua Portuguesa foi alvo de denúncias uma vez que se encontrava em um momento de "crise". A escola não estava conseguindo ensinar os alunos a ler e a escrever. Em vista disso, ampliaram-se os estudos e as pesquisas sobre o ensino, cabendo aos pesquisadores propor uma reflexão crítica das práticas escolares. O documento oficial, Guias curriculares para o ensino de $1^{\circ}$ grau do estado de São Paulo, de 1975, e a coletânea, O texto na sala de aula, organizada pelo linguista João Wanderlei Geraldi, de 1984, à época, foram algumas das ações realizadas com o intuito de minimizar a crise e, consequentemente, reformular o ensino de língua materna.

Esse momento de confronto entre as práticas escolares vistas como "tradicionais" e as pesquisas acadêmicas surtiu efeitos com a criação de vários documentos oficiais, como os Guias citados. Segundo Bunzen (2011), tais documentos

respondem aos questionamentos da academia priorizando no discurso oficial uma concepção sociointeracionista de língua(gem), atrelada a uma noção do texto como ponto de partida para o trabalho na escola, especialmente nas práticas de leitura, produção de texto e análise linguística. Além disso, a discussão do (não) ensino da gramática e do tratamento da variação linguística fecha o círculo de propostas de mudança em contraposição sempre a algo chamado de "ensino tradicional." (BUNZEN, 2011, p. 903) 
Assim, o fim dos anos 80, quando o ensino do Português na escola e as propostas dos livros didáticos de língua materna são alvo de críticas da academia, é marcado pela expansão das propostas curriculares estaduais para o ensino do Português e pela repercussão do Decreto Presidencial n. 91.372, de 1986. Além de estabelecer Diretrizes de promoção ao aperfeiçoamento do ensino e aprendizagem da Língua Portuguesa, esse documento recupera a denominação Português, passando a não ser mais Comunicação e Expressão em Língua Portuguesa.

Bunzen (2011) observa que, nessa época, houve uma espécie de flexibilidade do currículo e dos objetos de ensino, tendo em vista que persiste a ideia de que cabe ao professor fazer opção pelas atividades didáticas e pela organização/seleção dos objetos de ensino de acordo com seu planejamento de aula e elaboração de material didático.

No final do século XX, surgem os Parâmetros Curriculares Nacionais (PCN) e ocorre a reformulação do Programa Nacional do Livro Didático (PNLD). Ambos são políticas de governo dos anos 90 e procuraram dar continuidade a três processos inter-relacionados, a avaliação e distribuição de livros didáticos, a normatização/legitimação do ensino e estabelecimento de um sistema de avaliação na educação básica, conforme Bunzen (2011). A partir desse momento, passamos a comentar os PCN.

\section{PARÂMETROS CURRICULARES NACIONAIS (PCN)}

Os Parâmetros Curriculares Nacionais, editados pelo Ministério da Educação e do Desporto, foram elaborados com vista a atender a necessidade de uma revisão dos currículos orientadores dos trabalhos dos profissionais da educação no fim do século passado. Nesse período, a educação passou a ter um papel fundamental no desenvolvimento das pessoas e da sociedade.

A chegada de um novo milênio apontava para a necessidade de se discutir e pensar uma escola que estivesse voltada para a formação de cidadãos mais conscientes, críticos, reflexivos, enfim, aptos ao exercício da cidadania. O letramento, nesse momento, passou a ser essencial.

Nesse sentido, a intenção dos PCN foi ampliar e aprofundar uma discussão educacional protagonizada por pais, governos e sociedade para se atingir uma transformação no sistema educacional brasileiro. Além disso, os PCN, com o propósito de servir de apoio à reflexão sobre a prática pedagógica, ao planejamento das aulas, à análise e seleção de materiais didáticos e de recursos tecnológicos, tiveram o propósito de contribuir para a formação e atualização do profissional da educação. É de fato marcado como o primeiro documento oficial prescrito, composto de um aporte teórico consistente, de referência às práticas educacionais.

Os Parâmetros, portanto, caracterizam-se por serem uma orientação aos professores. Eles são divididos em disciplinas e discutem suas práticas de organização de conteúdo, formas de abordagem das matérias com os alunos, a aplicação das lições ensinadas e a conduta mais desejável a ser adotada pelos educadores em situações diversas.

No caso, os Parâmetros Curriculares Nacionais Terceiro e Quarto Ciclos do Ensino Fundamental de Língua Portuguesa têm a finalidade de constituir-se em referencial às discussões curriculares da área e, ao mesmo tempo, contribuir com técnicos e professores no processo de revisão e elaboração de propostas didáticas.

Esse documento está dividido em duas partes: Apresentação da área de Língua Portuguesa, na qual é apresentada a área e definidas as linhas gerais da proposta como natureza, características, importância da área, objetivos e conteúdos propostos para o ensino fundamental; e Língua Portuguesa no terceiro e no quarto ciclos em que são caracterizados o ensino e a aprendizagem de Língua Portuguesa nesses ciclos. Nessa parte, são definidos os seus objetivos e conteúdos, apresentadas as orientações didáticas, especificadas as relações existentes entre o ensino de Língua Portuguesa e as tecnologias da comunicação e, finalmente, são propostos critérios de avaliação.

No artigo intitulado O ensino de Língua Portuguesa e os $P C N^{\prime} S$, Santos (s/d) comenta que, na primeira parte dos PCN, a "língua portuguesa é apresentada como uma área em mudança, no que se refere ao ensino, pois 
tem se passado do excesso de regras e tradicionalismo típicos das escolas para um questionamento de regras e comportamentos linguísticos". (SANTOS, s/d)

Com relação à segunda parte, a referida autora chama a atenção do modo como os PCN apresentam as diferentes práticas de trabalho com a linguagem. Afirma que "a prática de escuta de textos orais / leitura de textos escritos, a prática de produção de textos orais e escritos e a prática de análise linguística formariam um tripé em cima do qual se sustenta o ensino da língua portuguesa, funcionando como um bloco de formação dos alunos". (SANTOS, s/d).

$\mathrm{Na}$ introdução do documento, esse aspecto é explicitado quando faz referência ao ensino da Língua Portuguesa na década de 60 e início da de 70 do século XX, orientado pela perspectiva gramatical, que foi contestado no início dos anos 80, quando as pesquisas produzidas por uma linguística independente da tradição normativa, entre outras, possibilitaram avanços na área.

As críticas mais frequentes dirigidas ao ensino, denominado "tradicional" de Língua Portuguesa, destacavam: i) a excessiva valorização da gramática normativa e a insistência nas regras de exceção; ii) o uso do texto como expediente para ensinar valores morais e como pretexto para o estudo da gramática; e iii) o fato de não considerarem a realidade e os interesses dos alunos. (PCN, 1998, p.18). Segundo Bunzen, "os PCN podem ser compreendidos como uma crítica ao dito 'ensino tradicional', apostando em um trabalho com a língua(gem) baseada nas práticas sociais.” (BUNZEN, 2011, p.905).

Os PCN para o ensino fundamental, portanto, estabelecendo o tex to como a unidade de ensino da Língua Portuguesa, conceituam a língua como uma atividade sociointeracional e histórica e dão ênfase ao domínio das práticas sociais de língua falada e de língua escrita, ao qual se subordina o estudo gramatical.

Dessa forma, os PCN dão conta de atender ao significativo número de teses e de trabalhos que defendiam uma revisão das práticas do ensino da Língua Portuguesa, legitimando um ensino que admita as variedades linguísticas e que valorize as hipóteses linguísticas elaboradas pelos alunos no processo de reflexão sobre a linguagem e para o trabalho com textos reais.

Enfim, os PCN se orientam para um currículo de Língua Portuguesa que enfoque práticas de usos da língua(gem) e de reflexão sobre os usos e aposta no texto como unidade de ensino e nos gêneros como objetos de ensino. Por isso, os conteúdos de língua portuguesa são articulados em torno de dois eixos básicos: o uso da língua oral e escrita; e a reflexão sobre a língua e a linguagem.

\section{ATRIBUIÇÕES DO PROFESSOR DE LÍNGUA PORTUGUESA: UMA ANÁLISE DOS PCN}

\subsection{Corpus da pesquisa e procedimento de análise}

Os Parâmetros Curriculares Nacionais - Terceiro e Quarto Ciclos - do Ensino Fundamental de Língua Portuguesa constituem o corpus de pesquisa deste trabalho.

Inicialmente, foi feita uma pesquisa de busca no documento da palavra-chave "professor(es)" com o auxílio do link "find", disponível no PDF (Portable Document Format). Após a seleção, procedemos à análise desse item lexical, no seu contexto, buscando identificar que atribuições do professor estão subjacentes aos PCN.

Delimitamos a busca e análise da palavra-chave particularmente em dois textos que compõem os PCN, a saber: A mediação do professor no trabalho com a linguagem e Tratamento didático dos conteúdos. Ambos compõem a segunda parte dos PCN e foram escolhidos, primeiro, por possuírem um número maior de ocorrências da palavra "professor(es)", se comparados aos demais textos; segundo, por discutirem temas relativos à função e à prática docentes, respectivamente. Nesses textos, portanto, as atribuições do professor são mais evidenciadas.

Para a realização deste trabalho, partimos da premissa de que é fundamental que o público a que se destinam os PCN, professores de ensino básico de Língua Portuguesa, realize uma leitura atenta do documento, se reconhecendo como uma das suas figuras essenciais. Acrescente-se a isso o fato de que os 
PCN, em sua função teleológica, constituem-se como uma orientação aos professores, uma vez que instigam à reflexão sobre a prática pedagógica, o que contribui sobremaneira com a formação e atualização docente.

\title{
4.2 Análise
}

\section{- A mediação do professor no trabalho com a linguagem (pág. 47 a 49)}

\author{
Recorte $n^{\circ} 1$ :
}

Nas situações de ensino de língua, a mediação do professor é fundamental: cabe a ele mostrar ao aluno a importância que, no processo de interlocução, a consideração real da palavra do outro assume, concordese com ela ou não. Por um lado, porque as opiniões do outro apresentam possibilidades de análise e reflexão sobre as suas próprias; por outro lado, porque, ao ter consideração pelo dizer do outro, o que o aluno demonstra é consideração pelo outro. (PCN, 1998, p. 47) (grifo nosso)

Nessa ocorrência está bem marcado que o professor é um "mediador" em sala de aula. A ele cabe o papel de mediar, nesse caso, o diálogo entre os participantes do processo de ensino e aprendizagem, buscando, por um lado, fazê-los perceber que a palavra de um influencia sobremaneira o outro e, por outro, levando-os a reconhecer que a opinião de um colega possibilita uma reflexão e análise de suas próprias.

Nesse confronto de ideias, a interação social é condição necessária da linguagem entre os alunos, a partir da qual seus valores, crenças e opiniões estão continuamente em (re)construção.

Nesse sentido, é fundamental que o professor tenha condições de depreender do texto que à noção de diálogo é conferida grande importância no processo de interação verbal em sala de aula, pois é tratado em um sentido mais amplo e não apenas como uma simples troca de informações, de opiniões, de ideias, etc, entre as pessoas.

\section{Recorte $n^{\circ}$ 2:}

Ao organizar o ensino, é fundamental que o professor tenha instrumentos para descrever a competência discursiva de seus alunos, no que diz respeito à escuta, leitura e produção de textos, de tal forma que não planeje o trabalho em função de um aluno ideal para o ciclo, muitas vezes padronizado pelos manuais didáticos, sob a pena de ensinar o que os alunos já sabem ou apresentar situações muito aquém de suas possibilidades e, dessa forma, não contribuir para o avanço necessário. (PCN, 1998, p. 48) (grifo nosso)

Nessa ocorrência, fortemente marcado pela forma verbal "tenha", é colocada ao professor uma necessidade fundamental no que diz respeito à organização das suas aulas: ter instrumentos que lhe apoiarão na descrição da "competência discursiva" de escuta, de leitura e de escrita de textos dos seus alunos.

Ainda, quanto à organização de ensino, prescreve-se que o professor não deve prever, no planejamento de aula, um aluno ideal. Provavelmente, esse profissional encontrará problemas na aplicação das suas atividades. Poderá se deparar tanto com alunos que já dominam determinado conteúdo quanto, pelo contrário, com os que estão bem à margem das suas expectativas. O professor, por isso, deve planejar suas aulas prevendo que seus alunos não são padronizados. Essa heterogeneidade da sala de aula, conforme está dito no trecho acima, muitas vezes, não é considerada no livro didático.

Recorte $n^{\circ}$ 3:

Nessa perspectiva, pode-se dizer que a boa situação de aprendizagem é aquela que apresenta conteúdos novos ou possibilidades de aprofundamento de conteúdos já tematizados, estando ancorada em conteúdos já constituídos. Organizá-la requer que o professor tenha clareza das finalidades colocadas para o ensino e dos conhecimentos que precisam ser construídos para alcançá-las. (PCN, 1998, p. 48) (grifo nosso)

Mais uma vez, nesse caso, o uso da forma verbal "tenha" implica uma necessidade do professor. Para dar conta de tudo o que foi colocado acima quanto à organização do ensino, precisa ter claras as "finalidades colocadas de ensino e dos conhecimentos que precisam ser construídos para alcançá-la”. Portanto, não é suficiente que o professor possua um bom planejamento de aula, além disso, são imprescindíveis que ele 
tenha clareza dos objetivos de suas aulas e que seja detentor de um embasamento teórico capaz de sustentar a sua prática.

\section{- Tratamento didático dos conteúdos (pág. 65 a 67)}

Recorte $n^{\circ}$ 4:

No caso da Língua Portuguesa, além dos aspectos já apontados, são decisivas para a aprendizagem as imagens que os alunos constituem sobre a relação que o professor estabelece com a própria linguagem. Por ter experiência mais ampla com a linguagem, principalmente se for, de fato, usuário da escrita, tendo boa relação com a leitura, gostando verdadeiramente de escrever, o professor pode se constituir em referência para o aluno. Além de ser quem ensina os conteúdos, é quem ensina, pela maneira como se relaciona com o texto e com o outro, o valor que a linguagem e o outro têm para si. (PCN, 1998, p. 66) (grifos nossos)

Enquanto, na primeira ocorrência da palavra "professor", a questão colocada em foco é a relação que o professor estabelece com a linguagem, na segunda, é discutida a relação do professor com a leitura e com o outro, no processo de interação.

Quanto ao primeiro caso, é de suma importância, para o aprendizado de Língua Portuguesa na escola, a forma como os alunos percebem a relação do professor de língua materna com a própria linguagem. E, quanto ao segundo, o professor, por possuir uma experiência com a linguagem maior que a de seus alunos, pode se constituir uma grande referência em sala de aula, desde que seja um usuário efetivo da escrita, tenha uma boa relação com a leitura e que goste "verdadeiramente". O uso do advérbio "verdadeiramente" marca que não basta dizer que gosta de ler aos alunos, é preciso que professor seja um leitor de fato. Isso deixa claro que o professor ensina não só pelo conteúdo, mas também pela forma como se relaciona com as questões implicadas na área, como a escrita e a leitura.

Recorte $n^{\circ} 5$ :

Para os alunos que provêm de comunidades com pouco ou nenhum acesso a materiais de leitura, ou que oferecem poucas possibilidades de participação em atos de leitura e escrita junto a adultos experientes, a escola poderá ser a única referência para a construção de um modelo de leitor e escritor. Isso só será possível se o professor assumir a condição de locutor privilegiado, que se coloca em disponibilidade para ensinar fazendo. (PCN, 1998, p. 66) (grifo nosso).

Na ocorrência de "professor" acima, é reforçada a questão abordada anteriormente, a de o professor ser uma referência de modelo de leitor e escritor. Porém, é discutido que essas responsabilidades aumentam quando seus alunos são oriundos de camadas sociais menos privilegiadas da sociedade. Com pouco acesso à leitura e à escrita, esses cidadãos têm como única referência o seu professor de Língua Portuguesa.

Recorte $n^{\circ}$ 06:

A formação de professores se coloca, portanto, como necessária para que a efetiva transformação do ensino se realize. Isso implica revisão e atualização dos currículos oferecidos na formação inicial do professor e a implementação de programas de formação continuada que cumpram não apenas a função de suprir as deficiências da formação inicial, mas que se constituam em espaços privilegiados de investigação didática, orientada para a produção de novos materiais, para a análise e reflexão sobre a prática docente, para transposição didática dos resultados de pesquisas realizadas na linguística e na educação em geral. (PCN, 1998, p. 67) (grifos nossos)

Nas ocorrências acima, está implícito que o professor é um agente de transformação do ensino. No entanto, ele necessita obter uma formação inicial de qualidade, que lhe proporcione os conhecimentos teóricopráticos necessários para atuar profissionalmente. Além disso, tem-se necessidade de programas de formação continuada aos professores para que possam obter a almejada atualização profissional. Nesse sentido, é possível pensar que isso garantiria uma melhora na qualidade do ensino da Língua Portuguesa na contemporaneidade uma vez que as prescrições dos PCN, de forma efetiva, estariam sendo assimiladas e colocadas em prática pelos docentes. 


\section{CONCLUSÃo}

O presente trabalho teve como objetivo investigar as atribuições do professor de Língua Portuguesa que estão subjacentes nos Parâmetros Curriculares Nacionais (PCN). Para isso, analisamos as ocorrências da palavra "professor(res)" em dois textos que compõem esse documento, a saber, A mediação do professor no trabalho com a linguagem e Tratamento didático dos conteúdos.

Nesse recorte estabelecido para a análise, verificamos que os PCN efetivamente propiciam a identificação das atribuições do professor do fim do século XX, de modo que lhe cabem os papéis de mediador, de modelo de leitor e de escritor e, também, de agente de transformação do ensino, norteando a realização de sua prática em sala de aula. Tais atribuições, contrapondo com aquelas do professor no percurso da emergente consolidação da Língua Portuguesa no Brasil, passam a valorizar a interação em sala de aula. Nesse sentido, cabe ao professor de Língua Portuguesa de Ensino Fundamental, preconizado pelos PCN, o papel de condutor da sua prática em sala de aula, partindo dos fundamentos da abordagem sociointeracionista da linguagem, segundo a qual a interação social possui papel fundamental na construção do indivíduo.

Portanto, o professor de Língua Portuguesa deve ser o mediador do processo ensino-aprendizagem de línguas, fazendo uso de estratégias que possibilitem ao aluno tornar-se independente, de modo que, enquanto professor ou mediador desse processo, possa preparar esse aprendiz para assumir o seu papel de agente em um espaço de diálogo e interação.

\section{REFERÊNCIAS}

ANGELO, G. Revisitando o ensino tradicional de Língua Portuguesa. 2005. 265. Tese (doutorado em Linguística Aplicada) - Universidade de Campinas, Campinas, 2005.

BUNZEN JR., C. S. A fabricação da disciplina escolar Português. Revista Diálogo Educacional, Curitiba, v. 11, n. 34, p. 885-911, set./dez. 2011.

PARÂMETROS CURRICULARES NACIONAIS - terceiro e quarto ciclos do ensino fundamental: língua portuguesa. Brasília: Secretaria de Educação Fundamental MEC, 1998.

PIETRI, E. Sobre a constituição da disciplina curricular de Língua Portuguesa. Revista Brasileira de Educação, v. 15, n. 43, jan./abr. 2010. Disponível em http://www.scielo.br/pdf/rbedu/v15n43/a05v15n43.pdf. Acesso em 03 de março de 2013.

Circulação de saberes e mediação institucional em documentos oficiais: análise de uma proposta curricular para o ensino de Língua Portuguesa. Currículo sem fronteiras, v. 7, n. 1, p. 263-283, jan./jun. 2007. Disponível em http://www.curriculosemfronteiras.org/vol7iss 1articles/pietri.pdf. Acesso em 03 de março de 2013.

SANTOS, L. W. O ensino de Lingua Portuguesa e os PCN'S. (S/D) Disponível em: http://www.filologia.org.br/viisenefil/06.htm. Acesso em: 01 de março de 2013.

SOARES, M. Português na escola: História de uma disciplina curricular. São Paulo: Loyola, 2002. p. 155-177.

Recebido em 14/05/13. Aprovado em 23/09/13. 